\title{
Regulation of Kv4.2 A-type potassium channels in HEK-293 cells by hypoxia
}

\author{
Yu-Qiang Liu ${ }^{1}$, Wen-Xian Huang ${ }^{1}$, Russell M. Sanchez ${ }^{2}$, Jia-Wei Min ${ }^{1}$, Jiang-Jian Hu ${ }^{1}$, Xiao-Hua He ${ }^{1}$ and \\ Bi-Wen Peng ${ }^{1 *}$
}

Department of Physiology, Hubei Provincial Key Laboratory of Developmentally Originated Disorder, School of Basic Medical Sciences, Wuhan University, Wuhan, China

${ }^{2}$ Department of Surgery, College of Medicine, Texas A\&M Health Science Center, Neuroscience Institute, Scott and White Hospital, Central Texas Veterans Health Care System, Temple, TX, USA

\section{Edited by:}

Mauro Pessia, University of Perugia,

Italy

\section{Reviewed by:}

Stefan H. Heinemann,

Friedrich-Schiller-Universität, Germany

Luigi Catacuzzeno, University of

Perugia, Italy

*Correspondence:

Bi-Wen Peng, Department of Physiology, School of Basic Medical

Sciences, Wuhan University, 185

Donghu Road, Wuhan, Hubei 430071,

China

e-mail:pengbiwen@whu.edu.cn
We previously observed that A-type potassium currents were decreased and membrane excitability increased in hippocampal dentate granule cells after neonatal global hypoxia associated with seizures. Here, we studied the effects of hypoxia on the function and expression of Kv4.2 and Kv4.3 a subunit channels, which encode rapidly inactivating Atype K currents, in transfected HEK-293 cells to determine if hypoxia alone could regulate $\mathrm{I}_{\mathrm{A}}$ in vitro. Global hypoxia in neonatal rat pups resulted in early decreased hippocampal expression of Kv4.2 mRNA and protein with 6 or $12 \mathrm{~h}$ post-hypoxia. Whole-cell voltageclamp recordings revealed that similar times after hypoxia $(1 \%)$ in vitro decreased peak currents mediated by recombinant Kv4.2 but not Kv4.3 channels. Hypoxia had no significant effect on the voltage-dependencies of activation and inactivation of Kv4.2 channels, but increased the time constant of activation. The same result was observed when Kv4.2 and Kv4.3 channels were co-expressed in a 1:1 ratio. These data suggested that hypoxia directly modulates A-type potassium channels of the subfamily typically expressed in principal hippocampal neurons, and does so in a manner to decrease function. Given the role of $I_{A}$ to slow action potential firing, these data are consistent with a direct effect of hypoxia to decrease $I_{A}$ as a mechanism of increased neuronal excitability and promotion of seizures.

Keywords: A-current, hypoxia, patch-clamp, in vitro

\section{INTRODUCTION}

Voltage-dependent potassium $(\mathrm{Kv})$ channels have a role in many developmental nervous system diseases, such as learning and cognitive impairment and epilepsy (Lawson, 2000; Wulff et al., 2009). A-type potassium channels are abundantly expressed in neurons and serve a number of functions, including regulation of excitability, fast-spiking, neurotransmitter release, and control of neural networks in physiological and pathophysiological processes (Birnbaum et al., 2004). A-type currents $\left(\mathrm{I}_{\mathrm{A}}\right)$ exhibit rapid activation, inactivation, and rapid recovery from inactivation at hyperpolarized membrane potentials (Jerng et al., 2004).

$\mathrm{Kv}$ channels are composed of pore-forming $\alpha$ proteins and auxiliary $\beta$ subunits (Patel and Honore, 2001; Conforti et al., 2003a). Among the $\mathrm{Kv} 4 \alpha$ subunits (Kv4.1, Kv4.2, and Kv4.3), Kv4.2 and $\mathrm{Kv} 4.3$ underlie the somatodendritic A-type $\mathrm{K}^{+}$currents in the central nervous system (CNS) (Huang et al., 2005), whereas, Kv4.1 mRNA levels are lower than Kv4.2 or Kv4.3 (Serodio and Rudy, 1998). In the hippocampus, Kv4.2 is mainly expressed in area CA1 pyramidal cells, and comprises the pore-forming subunit together with Kv4.3, whereas CA1 inhibitory interneurons express primarily Kv4.3 channels (Birnbaum et al., 2004). Downregulation of A-type $\mathrm{K}^{+}$channel function in pyramidal neuron dendrites increases neuronal excitability (Bernard et al., 2004), and selective blockade of A-type potassium channel can cause seizures (Ruschenschmidt et al., 2006).
The ability to sense and respond to hypoxia is critical for the survival of many cell types or tissues to their changing environment. In particular, $\mathrm{O}_{2}$-sensitive potassium channel expression has been studied in many chemosensitive cells such as carotid body, neuroepithelial body, pheochromocytoma (PC12), and pulmonary artery smooth muscle cells (Conforti et al., 2003b). Some potassium channel subtypes expressed in hypoxia-sensitive tissues have also been reported sensitive to low $\mathrm{pO}_{2}$ modulation in heterologous expression systems (Patel et al., 1997; Conforti et al., 2000). Recombinant Kv channels formed by several $\mathrm{Kv} \alpha$ subunits or $\alpha-\beta$ interactions have been reported to exhibit sensitivity to hypoxia. These include Kv1.2, Kv1.5, Kv2.1, Kv3.1b, Kv3.3, Kv1.2/Kv1.5, Kv2.1/Kv9.3, and Kv4.2/kv31.2 (Wang et al., 1996; Patel et al., 1997; Archer et al., 1998, 2001; Hulme et al., 1999; Perez-Garcia et al., 1999, 2000; Conforti et al., 2000; Osipenko et al., 2000; Lopez-Barneo et al., 2001). Co-expression of Kv $\beta 1.2$ has been reported to confer oxygen sensitivity to Kv 4.2 but not Kv1.3 channels in HEK-293 cells (Perez-Garcia et al., 1999). Furthermore, expression of a dominant-negative $\mathrm{Kv} 4$ construct (Kv4.xDN) can suppress the hypoxia-induced depolarization in chemoreceptive cells, suggesting direct effects of hypoxia on the Kv4 channel subfamily (Perez-Garcia et al., 2000). Notably, hypoxia can inhibit $\mathrm{O}_{2}$-sensitive $\mathrm{K}^{+}$channels via both inhibition of channel activity and down-regulation of the channel expression (Yuan, 2001; Conforti et al., 2003a). 
We previously reported that A-type $\mathrm{K}^{+}$currents were significantly decreased and membrane excitability was increased in hippocampal dentate granule cells after seizure-inducing hypoxia in vivo (Peng et al., 2013). However, the mechanisms that mediated this hypoxic inhibition remain to be elucidated. In the current study, we therefore investigated the mRNA and protein expression levels of the Kv4.2 and Kv4.3 after hypoxia treatment in rats. We further expressed Kv4.2 and co-expressed Kv4.2/Kv4.3 in HEK-293 cells to investigate a potential direct influence of hypoxia on the function of A-type channels.

\section{MATERIALS AND METHODS IN VIVO HYPOXIA TREATMENT}

Animals were obtained from the Animal Biosafety Level 3 Laboratory (ABSL-3) of Wuhan University. All experimental protocols were approved by the Committee on the Ethics of Animal Experiments of the Wuhan University (China). Rat pups on postnatal day 10 were removed from the litter and placed on a heating pad in a custom-made acrylic glass chamber with an $\mathrm{O}_{2}$ sensor mounted inside and three gas inlets for $\mathrm{N}_{2}$ infusion (Peng et al., 2013). For the treated pup, the chamber $\mathrm{O}_{2}$ concentration was lowered by $\mathrm{N}_{2}$ infusion to $7 \%$ within $30-40 \mathrm{~s}$, maintained at $6-7 \%$ for an additional $4 \mathrm{~min}$, lowered to $5-6 \%$ for $8 \mathrm{~min}$, and then lowered by $1 \%$ per minute until the pup became apneic for $30 \mathrm{~s}$, at which time the chamber lid was removed for exposure to room air. The total time of hypoxia exposure was $14-16 \mathrm{~min}$. Using this approach, hypoxia-treated pups typically exhibited spontaneous convulsive seizures lasting 10-60 s beginning 2-4 min after hypoxia onset, which recurred throughout hypoxia exposure and continued for several minutes after return to room air. Littermate controls were kept at room air and maintained body temperature by heating pad. All rats were immediately returned to their dam after the experiment. Animals were sacrificed for the brain sample at 6, 12, and $24 \mathrm{~h}$ after hypoxia treatment.

\section{QUANTITATIVE REAL TIME PCR ANALYSIS}

Total RNA was isolated from the whole hippocampus of rat using TRIzol Reagent (Invitrogen, Carlsbad, CA, USA) followed by chloroform extraction and isopropanol precipitation. RNA was quantified by spectrophotometric absorbency at $260 \mathrm{~nm}$, purity confirmed by A260/A280 ratio. RNA samples were stored at $-80^{\circ} \mathrm{C}$.

$\mathrm{Kv} 4.2$ and $\mathrm{Kv} 4.3$ cDNA was synthesized using $2 \mu \mathrm{g}$ of total RNA and a reverse transcription kit (Fermentas Canada Inc., Burlington, ON, Canada) with a $20 \mu \mathrm{l}$ reaction system. Quantitative PCR (BioRadMyIQ5; Life Technologies, Grand Island, NY, USA) was performed in a $0.2 \mathrm{ml}$ PCR tube (Axygen; VWR International, Radnor, PA, USA) containing $1 \mu \mathrm{L}$ of cDNA, $0.5 \mu \mathrm{L}$ of $10 \mu \mathrm{mol} / \mathrm{L}$ of each primer, $10 \mu \mathrm{L}$ of a $2 \times$ PCR mixture (All-in-One qPCR Mix; GeneCopoeia, Inc., Rockville, USA), $8 \mu \mathrm{L}$ of diethylpyrocarbonate $\mathrm{H}_{2} \mathrm{O}$ for a total volume of $20 \mu \mathrm{L}$. The reaction conditions for the quantitative PCR were $95^{\circ} \mathrm{C}$ for $10 \mathrm{~min}, 95^{\circ} \mathrm{C}$ denaturation for $10 \mathrm{~s}, 58^{\circ} \mathrm{C}$ renaturation for $20 \mathrm{~s}$, and $72^{\circ} \mathrm{C}$ extension for $25 \mathrm{~s}$ for a total of 40 cycles. Fluorescence was collected at $72^{\circ} \mathrm{C}$. The temperatures of the melting curve ranged from 72 to $95^{\circ} \mathrm{C}$, collecting fluorescence every $0.5^{\circ} \mathrm{C}$ for 47 cycles. The PCR primers for $\mathrm{Kv} 4.2$ were as follows: $5^{\prime}$-GTGTCAGGAAGTCATAGAGGC-3' (forward) and $5^{\prime}$-TTACAAAGCAGACACCCTGA-3' (reverse). The primers for $\mathrm{Kv} 4.3$ were $5^{\prime}$-CACCACCTGCTACACTGCTTAGAA-3' (forward) and 5'-TCTGCTCATCAATAAACTCGTGGTT-3' (reverse). The reference gene used was $\beta$-actin, and the two primers for this sequence were as follows: (forward) $5^{\prime}$-CACGATGGAGGGGCC GGACTCATC-3'; (reverse) 5' -TAAAGACCTCTATGCCAACACA GT- $3^{\prime}$. The data were analyzed using $2^{-\Delta \Delta \mathrm{Ct}}$ method to compare all groups in our experiments.

\section{WESTERN BLOT}

The samples were extracted from the whole hippocampus, homogenized with $2 \%$ SDS, $100 \mathrm{mM}$ dithiothreitol, and $10 \%$ glycerol and stored at $4^{\circ} \mathrm{C}$. Equal amount of proteins were loaded and separated on $10 \%$ SDS-PAGE. Then the proteins were transferred to a polyvinylidene fluoride (PVDF) membrane and blocked by immersion for $2 \mathrm{~h}$ in Tris-buffered saline (TBS) containing 5\% dry milk. The membranes were then incubated at $4^{\circ} \mathrm{C}$ overnight with rabbit polyclonal anti-Kv4.2 (Sigma, USA; used at 1:1000) and $\mathrm{Kv} 4.3$ receptor antibodies (Sigma, USA; used at 1:1000) and $\beta$ actin rat monoclonal antibody (Tianjin Sungene Biotech Co., Ltd, Tianjin, China; used at 1:2000). After incubation, the membranes were washed three-times with TBST (TBS containing $0.2 \%$ Tween20 ) and were then incubated again for $2 \mathrm{~h}$ with the goat anti-rat IgG (diluted 1:20,000) at room temperature. The membranes were washed again with TBST three-times. Finally, the reaction was developed using a chemiluminescent reagent (ECL; Ecl Advantage Inc., Menlo Park, CA, USA) and exposed to Hyper film (GE Healthcare Life Sciences, Pittsburgh, PA, USA).

\section{CELL TRANSFECTIONS AND TREATMENT WITH HYPOXIA}

Cell culture was carried out using standard procedures. HEK-293 cells were maintained in DMEM supplemented with $10 \%$ fetal calf serum (GIBCO BRL) and incubated in a humidified atmosphere containing $5 \% \mathrm{CO}_{2}$ in air at $37^{\circ} \mathrm{C}$. For transfections, $1 \mu \mathrm{g}$ of pcDNA3.0-Kv4.2 or pcDNA3.0-Kv4.2/Kv4.3 DNA into HEK293 cells was performed using Lipofectamine 2000 (Invitrogen) according to the instruction of the manufacturer. All experiments were recording HEK-293 cells within 20 passages. To study the effect of hypoxia on $\mathrm{K}^{+}$currents, cells after transfected were maintained in a modular incubator chamber (Billups-Rothenberg, Del Mar, CA, USA) at $37^{\circ} \mathrm{C}$ with $1 \% \mathrm{O}_{2}$ for 6 or $12 \mathrm{~h}$. Cells transfected for $24 \mathrm{~h}$ total were used for electrophysiological recordings, with hypoxia exposure carried during the final 6 or $12 \mathrm{~h}$ of incubation.

\section{ELECTROPHYSIOLOGICAL RECORDINGS}

$\mathrm{K}^{+}$currents were studied using the whole-cell patch-clamp technique and voltage-clamp recordings were carried out at room temperature $\left(22-25^{\circ} \mathrm{C}\right)$ by using a MultiClamp-700B amplifier and Digidata-1440A A/D converter (Axon Instruments, CA, USA). Recording electrodes were pulled using a Sutter P-97 puller (Sutter Instruments, CA, USA). Electrodes were filled with intracellular solution containing (in millimolar): $125 \mathrm{KCl}, 4 \mathrm{MgCl}_{2}, 10 \mathrm{HEPES}$, $10 \mathrm{EGTA}$, and $5 \mathrm{MgATP}$, adjusted to $310 \mathrm{mOsm} / \mathrm{L}$ with sucrose, $\mathrm{pH} 7.2$ with $\mathrm{KOH}$. The external solution contained (in millimolar): $141 \mathrm{NaCl}, 4.7 \mathrm{KCl}, 1.2 \mathrm{MgCl}_{2}, 1.8 \mathrm{CaCl}_{2}, 10$ glucose, and 10 HEPES, adjusted to $330 \mathrm{mOsm} / \mathrm{L}$ with sucrose, $\mathrm{pH} 7.4$ with $\mathrm{NaOH}$. The resistance of the recording pipette filled with internal solution was 2-6 M $\Omega$. The adjustment of capacitance compensation 
and series resistance compensation was done before recording the membrane currents. The holding potential was $-80 \mathrm{mV}$. Isolated HEK-293 cells were studied $24 \mathrm{~h}$ after transfection. Membrane currents were filtered at $2 \mathrm{kHz}$ and digitized at $10 \mathrm{kHz}$, and the data were stored in compatible PC computer for off-online analysis using the pCLAMP 10 acquisition software (Axon Instruments, CA, USA).

The voltage-dependence of activation was studied by a $400 \mathrm{~ms}$ constant depolarizing pulse from $-50 \mathrm{mV}$ to $+40 \mathrm{mV}$ in $10 \mathrm{mV}$ steps (see Figure 2A inset). To determine the voltage-dependence of steady-state inactivation of $\mathrm{Kv} 4.2$, the voltage-dependence of inactivation was assessed by measuring the peak amplitude of current responses evoked by test depolarization to $+40 \mathrm{mV}$ after $1.5 \mathrm{~s}$ pre-pulse to potentials between -110 and $0 \mathrm{mV}$ with $10 \mathrm{mV}$ increment (see Figure 2B inset).

\section{DATA ANALYSIS}

All data were analyzed by Igor Pro 6.10 (Wavemetrics, Lake Oswego, OR, USA), pCLAMP 10 (Axon Instruments, CA, USA) and Origin 7.5 (Microcal Software, USA). To construct steadystate activation curves, peak currents $(I)$ were converted into conductance $(G)$ using the formula: $G=I /\left(\mathrm{V}_{\mathrm{m}}-\mathrm{V}_{\text {rev }}\right)$, where $\mathrm{V}_{\mathrm{m}}$ is the membrane potential, and $\mathrm{V}_{\text {rev }}$ is the reversal potential $(-90 \mathrm{mV}$ in our experiments). The normalized conductance was fitted by a Boltzmann Equation: $G / \mathrm{Gmax}=1 /\{1+\exp$ $\left.\left[\left(\mathrm{V}_{\mathrm{m}}-\mathrm{V}_{1 / 2}\right) / k\right]\right\}$, where $\mathrm{V}_{1 / 2}$ is the half-maximal membrane potential for activation and $k$ is the slope factor. The steadystate inactivation curves were established using a Boltzmann equation: $I / \operatorname{Imax}=1 /\left\{1+\exp \left[\left(\mathrm{V}_{\mathrm{m}}-\mathrm{V}_{1 / 2}\right) / k\right]\right\}$, where $\mathrm{V}_{1 / 2}$ is the half-maximal membrane potential for inactivation and $k$ is the slope factor. Mono- or bi-exponential functions were used to fit current rise time and decay time, respectively, using one of the following equations: $y(t)=A_{1} \exp (-t / \tau)+B$ or $y(t)=$ $A_{1} \exp \left(-t / \tau_{1}\right)+A_{2} \exp \left(-t / \tau_{2}\right)+B$, where $t$ is time, $A_{1}$ and $A_{2}$ are the amplitudes, and $\tau_{1}$ and $\tau_{2}$ are the time constants of decay.

All data reported in this study are expressed as means \pm SEM, Statistical significance was verified using one-way ANOVA test and Student's $t$-test. $P<0.05$ was the evaluation criterion for statistical significance.

\section{RESULTS}

\section{HYPOXIA TREATMENT DECREASED Kv4.2 EXPRESSION IN RAT HIPPOCAMPUS}

First, we examined the expression of $\mathrm{Kv} 4.2$ and $\mathrm{Kv} 4.3$ after hypoxia treatment in neonatal rat pups. Kv4.2 and Kv4.3 mRNA and protein from hippocampal tissue before or at 6, 12, and $24 \mathrm{~h}$ after hypoxia treatment were analyzed by qPCR and western blot (Figure 1). The levels of Kv4.2 mRNA and protein were significantly decreased by hypoxia treatment at each time point we tested (Figures 1A,B). 6, 12, and $24 \mathrm{~h}$ after the hypoxia treatment, Kv4.2 mRNA was decreased by $35 \%(n=3, p<0.05$ vs. control), $68 \%$ ( $n=3, p<0.01$ vs. control), and $84 \%(n=3, p<0.01$ vs. control), respectively, and $\mathrm{Kv} 4.2$ protein was decreased by $22 \%$ ( $n=3, p<0.05$ vs. control), $21 \%$ ( $n=3, p<0.05$ vs. control), and $43 \%$ ( $n=3, p<0.01$ vs. control), respectively. The hypoxia-induced reduction of Kv4.2 mRNA was clearly timedependent (Figure 1A), with a significant reduction observed $6 \mathrm{~h}$ after hypoxia treatment, and a larger reduction at 12 and $24 \mathrm{~h}$ post-hypoxia exposure. However, there was no marked difference between 12 and $24 \mathrm{~h}$ post-hypoxia treatment. In contrast, Kv4.3 mRNA was comparably decreased across all time points tested, with no further decrease up to 1 day post-hypoxia (Figure 1C). Notably, Kv4.3 protein was not significantly altered within $24 \mathrm{~h}$ after hypoxia treatment (Figure 1D).

\section{HYPOXICSUPPRESSION OF Kv4.2 CHANNEL-MEDIATED CURRENT}

Whole-cell patch-clamp recording was performed on HEK-293 cells transfected with Kv4.2. As shown in Figures 2A-C, Kv4.2 channel currents exhibited rapid activation and inactivation typical of A-type potassium currents. Since there was no significant difference in mRNA and protein between 12 and $24 \mathrm{~h}$ after hypoxia treatment in vivo, we examined the properties of Kv4.2 channel currents at only 6 and $12 \mathrm{~h}$ after hypoxia treatment. Peak Kv4.2 channel-mediated current amplitudes were significantly decreased at 6 and $12 \mathrm{~h}$ after hypoxia treatment. The peak current amplitude was $2.55 \pm 0.54 \mathrm{nA}(n=10)$ at $+40 \mathrm{mV}$ in the control group and $1.70 \pm 0.52 \mathrm{nA}(n=10, P<0.01)$ and $1.46 \pm 0.17 \mathrm{nA}(n=13$, $P<0.01)$ at 6 and $12 \mathrm{~h}$ after hypoxia treatment, respectively (Figure 2C).

We next investigated the effect of hypoxia on Kv4.2 channel gating properties (Figure 2). Figure 2D shows that hypoxia did not significantly alter the voltage-dependent activation of Kv4.2 channels. Single Boltzmann distribution fits showed that Kv4.2 channels under control conditions exhibited a voltage of half-maximum activation $\left(\mathrm{V}_{1 / 2}\right)$ of $\mathrm{V}_{1 / 2}=-3.26 \pm 0.96 \mathrm{mV}$ and a $k_{\text {act }}$ of $15.95 \pm 0.89 \mathrm{mV}(n=7)$. No significant changes in $\mathrm{V}_{1 / 2}$ and $k$ were detected at 6 and $12 \mathrm{~h}$ after hypoxia $\left(\mathrm{V}_{1 / 2}=-5.42 \pm 1.56 \mathrm{mV}, k=18.71 \pm 1.51 \mathrm{mV}, \quad n=8\right.$; $\mathrm{V}_{1 / 2}=-5.59 \pm 1.64 \mathrm{mV}, \quad k=19.12 \pm 1.60 \mathrm{mV}, \quad n=11$, respectively) (Table 1). For steady-state inactivation (Figure 2E), the $\mathrm{V}_{1 / 2}$ of the inactivation removal also did not shift significantly, and was $-54.66 \pm 1.48 \mathrm{mV}(n=6)$ for controls vs. $-55.96 \pm 1.09 \mathrm{mV}$ ( $n=8, P>0.05,6 \mathrm{~h}$ hypoxia vs. control) and $-53.84 \pm 0.72 \mathrm{mV}$ ( $n=7, P>0.0512 \mathrm{~h}$ hypoxia vs. control) after 6 and $12 \mathrm{~h}$ hypoxia, respectively (Table $\mathbf{1})$. The activation slope factor $(k)$ also was not significantly different between control and hypoxia groups.

To characterize the rate of activation of the Kv4.2-induced currents in HEK-293 cells, the rising phases of Kv4.2 currents evoked at test potentials between 0 and $+40 \mathrm{mV}$ were fitted by single exponential function after the onset of the voltage step to the peak of the outward current. As is evident, the Kv4.2-induced currents activate rapidly, and the activation time constants vary with voltage, decreasing with increasing membrane depolarization (Figure 2F). However, the Kv4.2-induced currents activate more slowly after hypoxia treatment. Figure $2 \mathrm{G}$ showed that the activation time constant evoked at $+40 \mathrm{mV}$ in control was increased at 6 and $12 \mathrm{~h}$ after hypoxia treatment from $1.23 \pm 0.17 \mathrm{~ms}(n=6)$ to $1.68 \pm 0.13 \mathrm{~ms}$ $(n=7, p<0.05$ vs. control) and $2.19 \pm 0.22 \mathrm{~ms}(n=10, p<0.01$ vs. control), respectively (Table 1). Next, we investigated the decay kinetics of Kv4.2 currents evoked at $+40 \mathrm{mV}$. The decay phase of the currents could be well fitted by a bi-exponential function, yielding fast and slow-decay time constants. As shown in Figure $\mathbf{2 H}$, neither $\tau_{\text {fast }}$ nor $\tau_{\text {slow }}$ displayed a significant change after hypoxia treatment. 


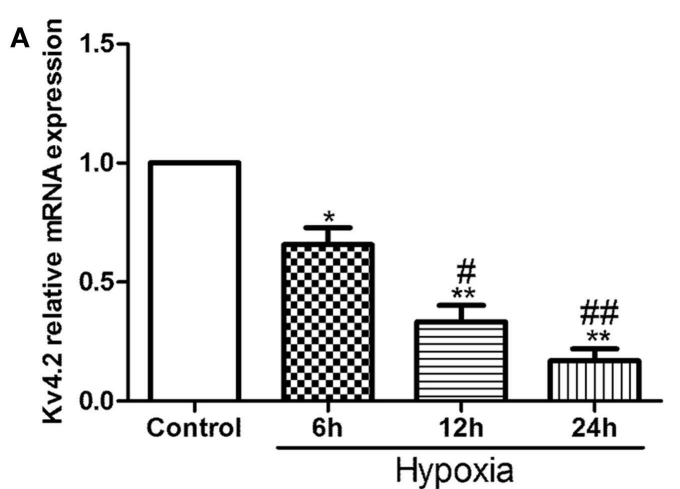

B
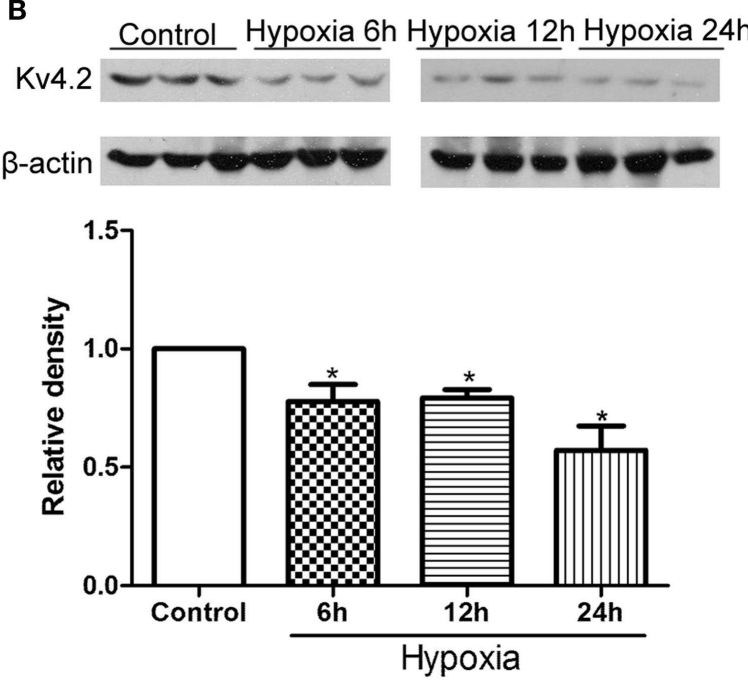

FIGURE 1 | Effect of hypoxia on the mRNA and protein levels of Kv4.2 and Kv4.3. Quantification of mRNA levels of Kv4.2 (A) and Kv4.3 (C).

Representative image and quantification of protein levels of Kv4.2 (B) and Kv4.3 (D) in control and hypoxia groups. Equal amounts of collected protein
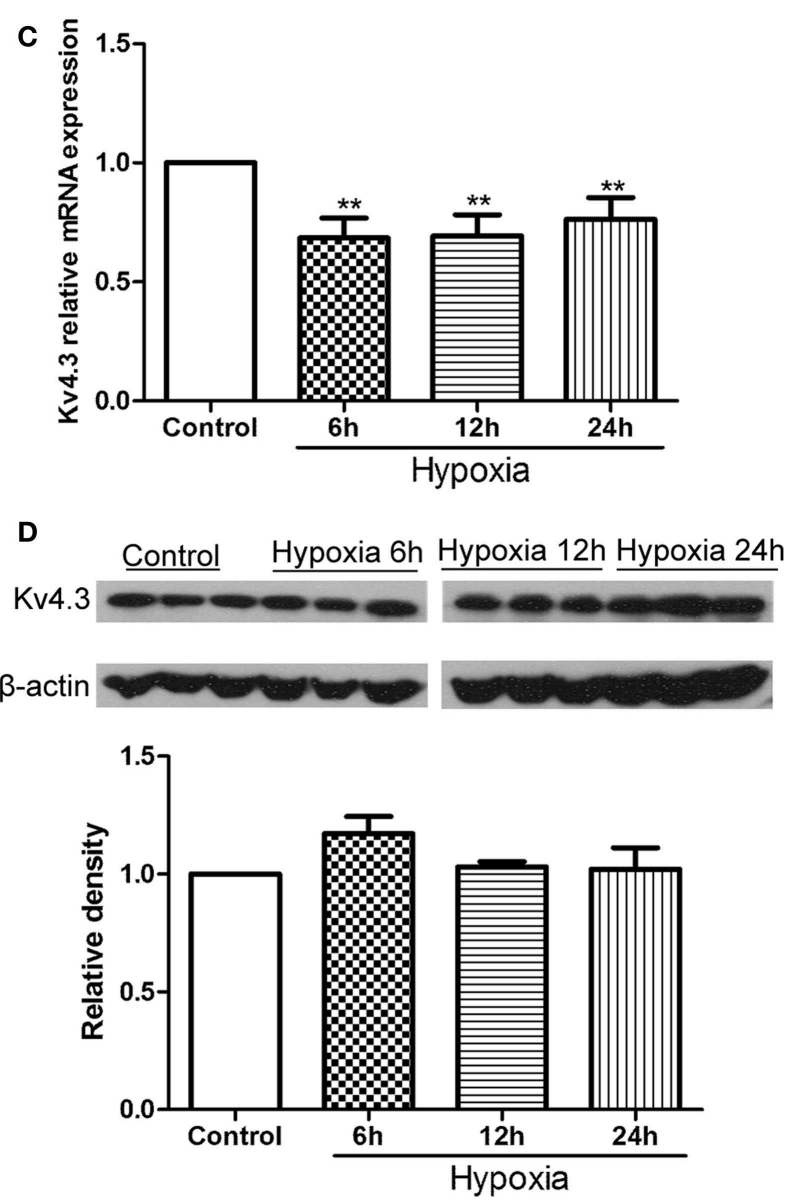

samples were subjected to Western immunoblot analysis. $\beta$-Actin was used as an internal control. Data are presented as means \pm SEM $(n=3$ for protein and mRNA in each group). ${ }^{*} p<0.05,{ }^{*} p<0.01$ vs. control. ${ }^{*} p<0.05$, $\# p<0.01$ vs. hypoxia $6 \mathrm{~h}$.
To determine the rates of Kv4.2 recovery from steady-state inactivation, cells were first depolarized to $+40 \mathrm{mV}$ for $1 \mathrm{~s}$ (to inactivate the currents), then hyperpolarized to $-110 \mathrm{mV}$ for varying times (ranging from 10 to $200 \mathrm{~ms}$ ) prior to test depolarizations to $+40 \mathrm{mV}$ (to assess recovery). Recovery curves were generated by plotting normalized current amplitudes (normalized to maximum) of activation as a function of pre-pulse time and fitting with a single exponential. At $-110 \mathrm{mV}$, the recovery time constant in control was $94.84 \pm 9.94 \mathrm{~ms}(n=8)$ (Figure 3A). The recovery time constant at $6,12 \mathrm{~h}$ after hypoxia treatment were not significantly changed $(91.24 \pm 12.90 \mathrm{~ms}, n=10, p>0.05$, $6 \mathrm{~h}$ vs. control; $86.32 \pm 8.36 \mathrm{~ms}, n=10, p>0.05,12 \mathrm{~h}$ vs. control) (Table 1). Therefore, except for the time to activation, most biophysical features of Kv4.2 currents remained unchanged after hypoxia.

\section{EFFECTS OF HYPOXIA ON HETEROMERIC Kv4.2/Kv4.3 CHANNELS IN HEK-293 CELLS}

Although the experiments described above revealed that hypoxia altered mRNA and protein levels of Kv4.2 and the Kv4.3 mRNA, it remained unclear whether hypoxia could affect the function of heteromeric Kv4.2/Kv4.3 channels. To determine the biophysical properties of heteromeric Kv4.2/Kv4.3 channels, Kv4.2 + Kv4.3 (in a ratio of 1:1) and EGFP were induced into HEK-293 cells, and whole-cell recordings were obtained from EGFP-positive cells $24 \mathrm{~h}$ after transfection. As shown in Figures 4A,B, co-expression of $\mathrm{Kv} 4.2$ and $\mathrm{Kv} 4.3$ resulted in rapidly activating and inactivating $\mathrm{K}^{+}$currents typical of $\mathrm{I}_{\mathrm{A}}$. The amplitudes and voltagedependence of activation and inactivation were examined as described above for Kv4.2. Similarly, peak currents (at $+40 \mathrm{mV}$ ) were significantly decreased at 6 and $12 \mathrm{~h}$ after hypoxia treatment compared to controls [Control $=6.72 \pm 0.47 \mathrm{nA}(n=8) ; 6 \mathrm{~h}$ Hypoxia $=5.11 \pm 0.70 \mathrm{nA}, n=8, p<0.01$ vs. control; and $12 \mathrm{~h}$ Hypoxia $=4.79 \pm 0.89 \mathrm{nA}, n=9, p<0.01$ vs. control; Figure 4C].

Similar to the effect on Kv4.2 activation, hypoxia did not significantly alter the voltage-dependence of activation for Kv4.2/Kv4.3 channels (Figure 4D). The $\mathrm{V}_{1 / 2}$ of $\mathrm{Kv} 4.2 / \mathrm{Kv} 4.3$ currents in the control group was $-10.25 \pm 0.65 \mathrm{mV}(n=8)$ compared to $-7.36 \pm 0.70 \mathrm{mV} \quad(n=7, p>0.05$ vs. control) and $-7.48 \pm 0.80 \mathrm{mV}(n=8, p>0.05$ vs. control $)$ at 6 and 


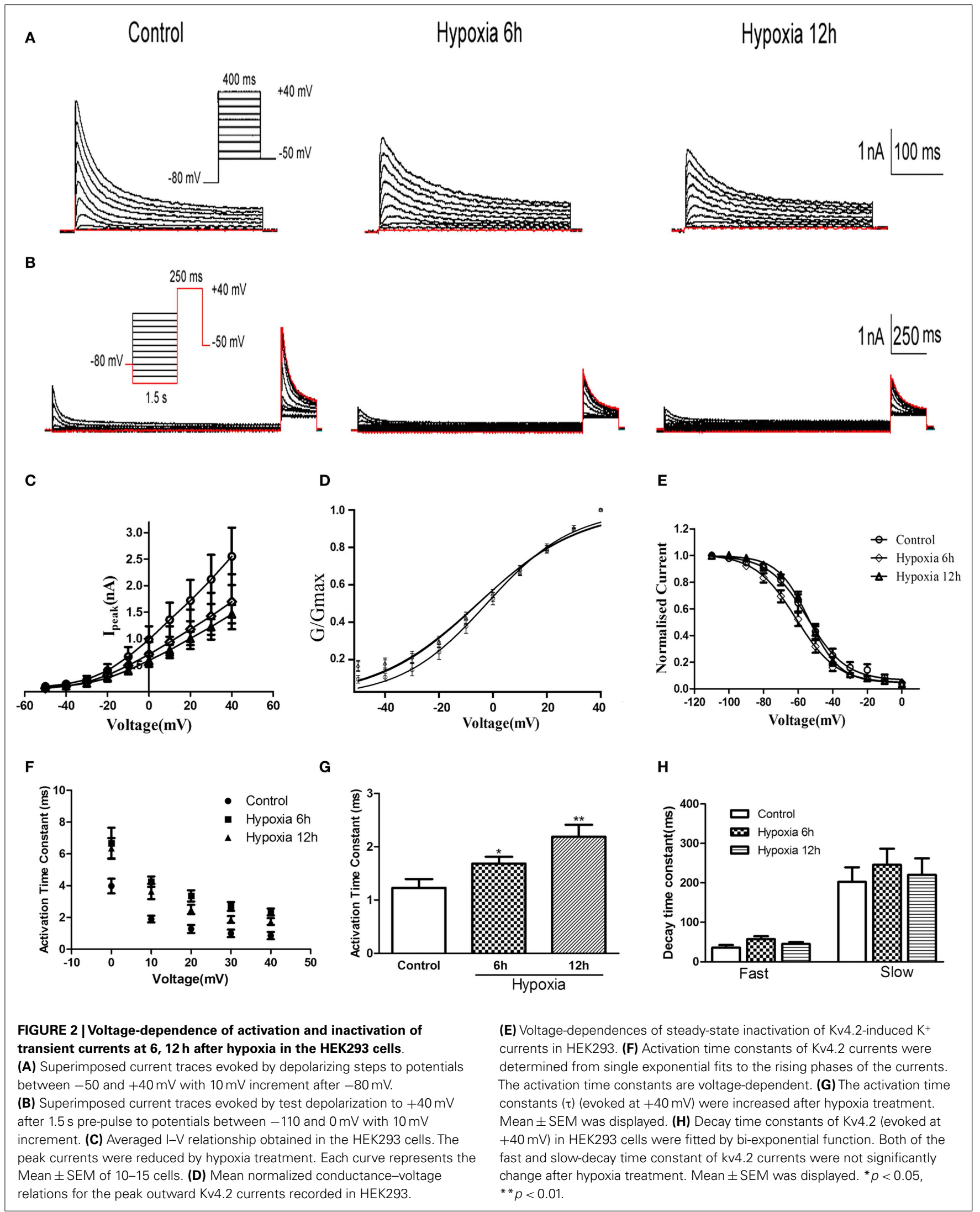


Table 1 | Comparison of properties of Kv4-induced $\mathrm{K}^{+}$currents.

\begin{tabular}{|c|c|c|c|c|c|c|}
\hline & \multicolumn{2}{|c|}{ Control } & \multicolumn{2}{|c|}{ Hypoxia $6 \mathrm{~h}$} & \multicolumn{2}{|c|}{ Hypoxia $12 \mathrm{~h}$} \\
\hline & Kv4.2 & Kv4.2/Kv4.3 & Kv4.2 & Kv4.2/Kv4.3 & Kv4.2 & Kv4.2/Kv4.3 \\
\hline$k_{\text {act }}$ & $15.95 \pm 0.89$ & $15.97 \pm 0.60$ & $18.71 \pm 1.51$ & $15.89 \pm 0.64$ & $19.12 \pm 1.60$ & $15.961 \pm 0.74$ \\
\hline Activation T (ms) $(+40 \mathrm{mV})$ & $1.23 \pm 0.17$ & $0.97 \pm 0.04$ & $1.68 \pm 0.13^{*}$ & $2.53 \pm 0.23^{* * *}$ & $2.19 \pm 0.22^{* *}$ & $1.99 \pm 0.23^{* * *}$ \\
\hline $\mathrm{V}_{1 / 2}$ inactivation $(\mathrm{mV})$ & $-54.66 \pm 1.48$ & $-42.07 \pm 0.72$ & $-55.96 \pm 1.09$ & $-45.58 \pm 0.74$ & $-53.84 \pm 0.72$ & $-49.37 \pm 0.73$ \\
\hline Inactivation T (ms) & $35.97 \pm 6.36$ & $36.48 \pm 1.99$ & $57.45 \pm 7.39$ & $49.63 \pm 5.35$ & $44.64 \pm 4.97$ & $35.97 \pm 6.36$ \\
\hline$(+40 \mathrm{mV})$ & $202.60 \pm 36.78$ & $200.80 \pm 22.28$ & $245.90 \pm 40.84$ & $233.50 \pm 46.28$ & $220.70 \pm 41.49$ & $213.00 \pm 35.91$ \\
\hline Recovery $\tau(\mathrm{ms})$ & $94.84 \pm 9.94$ & $37.26 \pm 4.83$ & $91.24 \pm 12.9$ & $93.15 \pm 15.22 * * *$ & $86.32 \pm 8.36$ & $66.55 \pm 7.44^{* *}$ \\
\hline
\end{tabular}

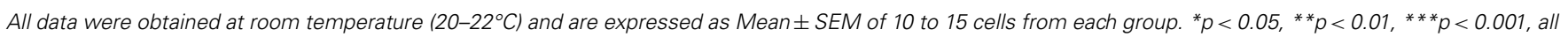
compared with control.

$12 \mathrm{~h}$ after hypoxia treatment, respectively (Table 1 ). The activation slope factor $(k)$ was also not significantly different between control and hypoxia groups. Hypoxia had no significant effect on the inactivation of $\mathrm{Kv} 4.2 / \mathrm{Kv} 4.3$ channels (Figure 4E). The inactivation $\mathrm{V}_{1 / 2}$ and $k$ of $\mathrm{Kv} 4.2 / \mathrm{Kv} 4.3$ was not significantly different between control and hypoxia groups (Control: $\mathrm{V}_{1 / 2}=-42.07 \pm 0.72 \mathrm{mV}, k=-0.07 \pm 0.007 \mathrm{mV}, n=8 ; 6 \mathrm{~h}$ : $\mathrm{V}_{1 / 2}=-45.58 \pm 0.74 \mathrm{mV}, k=-0.06 \pm 0.005 \mathrm{mV}, n=8, p>0.05$ vs. control; $12 \mathrm{~h}: \mathrm{V}_{1 / 2}=-49.37 \pm 0.73 \mathrm{mV}, k=-0.05 \pm 0.004 \mathrm{mV}$, $n=8, p>0.05$ vs. control) (Table 1 ).

In addition, the rising and decay phases of the $\mathrm{Kv} 4.2 / \mathrm{Kv} 4.3$ currents were described by single or double exponentials. Similar to the results for Kv4.2 (Figure 2F), the Kv4.2/Kv4.3-induced currents activate rapidly, and the activation time constants vary with voltage, decreasing with increasing membrane depolarization (Figure 4F). However, the Kv4.2-induced currents activate more slowly after hypoxia treatment. At $+40 \mathrm{mV}$, the activation time constant in the control group was significantly increased at 6 and $12 \mathrm{~h}$ after hypoxia treatment from $0.97 \pm 0.04 \mathrm{~ms}(n=10)$ to $2.53 \pm 0.23 \mathrm{~ms}(n=8, p<0.001$ vs. control) and $1.99 \pm 0.23 \mathrm{~ms}$ ( $n=7, p<0.001$ vs. control), respectively (Figure 4G) (Table 1). However, hypoxia had no significant effect on the fast and slow-decay time constants (Figure $\mathbf{4 H}$ ).

To determine the rates of heteromeric $\mathrm{Kv} 4.2 / \mathrm{Kv} 4.3$ recovery from steady-state inactivation, we used a same depolarized step protocol as in Figure 3A. The recovery curves were fitted with mono-exponential function. Notably, co-expression of Kv4.2 and Kv4.3-induced currents recovered faster from steady-state inactivation than Kv4.2-mediated currents (Figure 3B). However, the inactivation recovery rates for heteromeric Kv4.2/Kv4.3-mediated currents were significantly slowed after hypoxia treatment compared to control $(p<0.01)$ (Table 1$)$.

\section{DISCUSSION}

The current study showed that hypoxia down-regulated $\mathrm{I}_{\mathrm{A}}$ in vitro. In addition, hypoxia increased the time constant of activation without significantly altering the voltage-dependence of activation and inactivation. Furthermore, hypoxia had similar effects on co-expressed Kv4.2 and Kv4.3 channels. Importantly, we also observed that hypoxia in vivo decreased the expression of $\mathrm{Kv} 4.2$ and $\mathrm{Kv} 4.3$ in the hippocampus, providing a possible mechanism of $\mathrm{I}_{\mathrm{A}}$ inhibition observed previously after global hypoxia [see Patel et al. (1997)].

Neuronal ion channels can have complex roles in hypoxiainduced injury. Some ion channels are up-regulated by hypoxia such as Kv2.1 (Misonou et al., 2005; Ito et al., 2010), but some are down-regulated such as Ca-dependent $\mathrm{K}^{+}\left(\mathrm{K}_{\mathrm{Ca}}\right)$ channels, ATP-sensitive potassium $\left(\mathrm{K}_{\mathrm{ATP}}\right)$ channel, voltage-sensitive sodium channels (VSSCs), voltage-gated $\mathrm{Ca}^{2+}$ channels (VGCCs) (Melamed-Frank et al., 2001; Gao and Fung, 2002; Banasiak et al., 2004; Chao and Xia, 2010).

As expected, heterologously expressed Kv4.2 and Kv4.3 $\alpha$ subunits showed properties of $\mathrm{I}_{\mathrm{A}}$ (rapid activation and inactivation) (Birnbaum et al., 2004). Previous studies have shown that $\mathrm{I}_{\mathrm{A}}$ can be regulated by hypoxia/ischemia, but the functional significance of this change is speculative (Cummins et al., 1991; Hyllienmark and Brismar, 1996; Gebhardt and Heinemann, 1999; Chi and $\mathrm{Xu}, 2000) . \mathrm{I}_{\mathrm{A}}$ and other $\mathrm{K}^{+}$currents were transiently increased after ischemia/reperfusion in vivo (Chi and $\mathrm{Xu}, 2000$ ), yet brain slices exposed to hypoxia in vitro resulted in inhibition of $\mathrm{K}^{+}$ currents (Cummins et al., 1991; Hyllienmark and Brismar, 1996; Gebhardt and Heinemann, 1999). Consistent with the latter, our data showed that $\mathrm{I}_{\mathrm{A}}$ was decreased after hypoxia treatment in an in vitro expression system. One possible mechanism underlying the reduction of potassium currents is that the number of $\mathrm{K}^{+}$ channels decreased after hypoxia treatment. Kv1.3 protein levels were observed to decrease in Jurkat $\mathrm{T}$ cells after hypoxia, with the hypoxic down-regulation of Kv1.3 expression depending on hypoxia severity, indicating that the number of Kv channels could be altered by hypoxia (Conforti et al., 2003a). Moreover, hypoxia down-regulated the transcription and expression of Kv1.2 and Kv1.5 in rat pulmonary arterial smooth muscle cells (PASMC) (Wang et al., 1997). The human embryonic kidney cells (HEK293) have been widely used as one mammalian expression system in the study of $\mathrm{Kv}$ channels. It's important to acknowledge the possibility that endogenous $\mathrm{K}$ channels could contribute to currents measured through the heterologously expressed Kv channels in these cells. However, HEK-293 do not endogenously express 

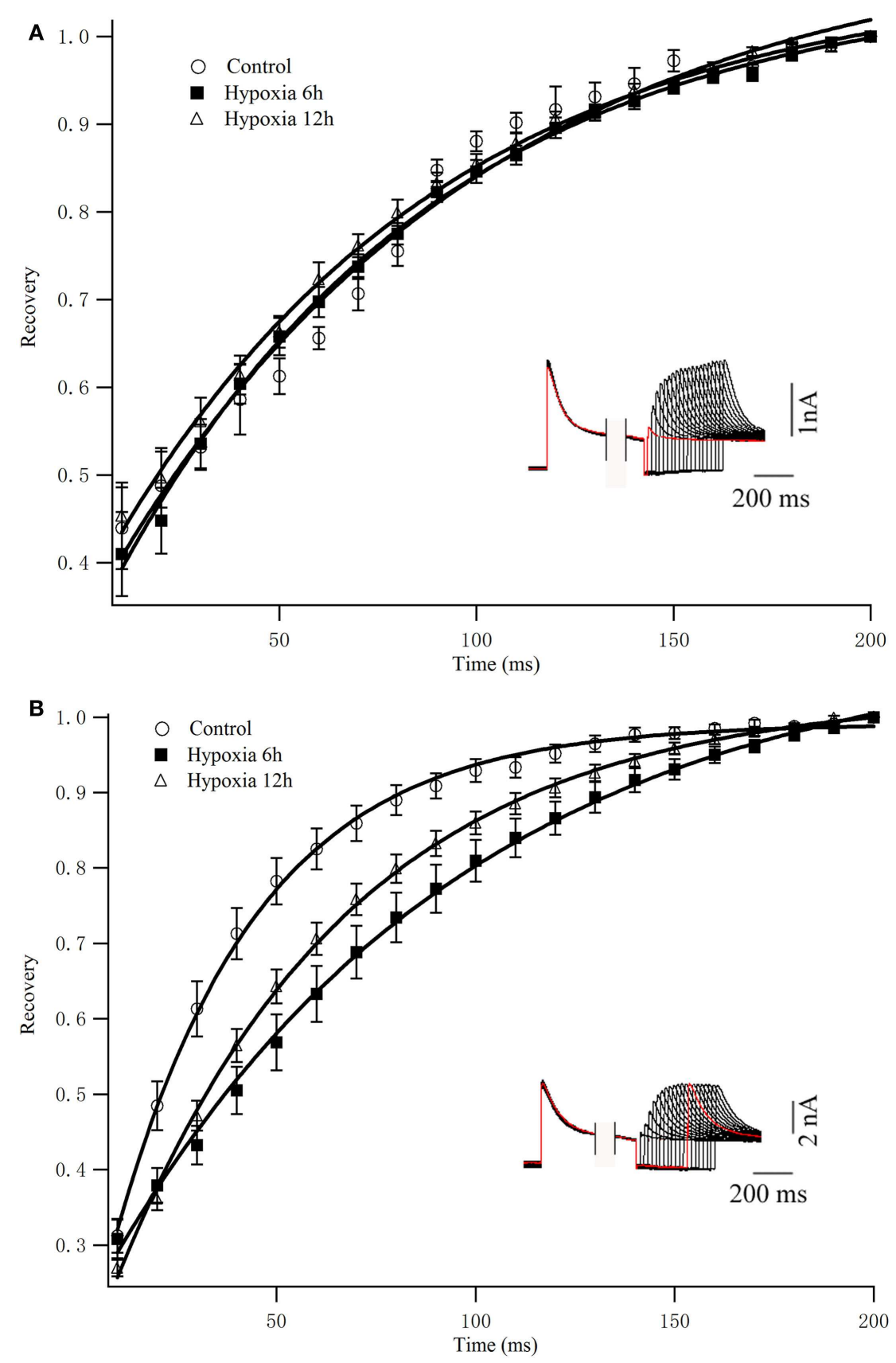

FIGURE 3 | Recovery from inactivation of Kv4.2 and co-expression of Kv4.2/Kv4.3. (A) Inactivation recovery was examined by inactivating Kv4.2 (A) and Kv4.2/Kv4.3 (B) current and then stepping to $-110 \mathrm{mV}$ for

increasing before a test step to $40 \mathrm{mV}$. Mean \pm SEM normalized currents in HEK-293 $(n=10)$ cells are plotted as a function of recovery time. Data points were fitted with mono-exponential. Inset represents the exemplificative experimental traces of Kv4.2 (A) and Kv4.2/Kv4.3 (B) in control group.
$\mathrm{I}_{\mathrm{A}}$-encoding genes (Kv1.4, Kv3.3, Kv3.4, and Kv4.1) (Jiang et al., 2002; Thomas and Smart, 2005). Also, as a blank control, we recorded from HEK-293 cells that were transfected with the reporter gene GFP without the Kv subunits (same protocol as shown in Figure 2A). The average amplitude of the depolarizationactivated current was $<500 \mathrm{pA}$, with a slow-activation phase and slow-decay phase, very different from A-type potassium channel (as shown in Figure S1 in Supplementary Material). Thus, in the current study, we demonstrated that Kv4.2 and Kv4.3 mRNA and protein were decreased by hypoxia, supporting decreased channels as a mechanism of $\mathrm{I}_{\mathrm{A}}$ inhibition.

Another possibility is that channel properties, such as the open probability and opening time, were altered after hypoxia treatment. The redox state of amino acid residues in channel proteins 


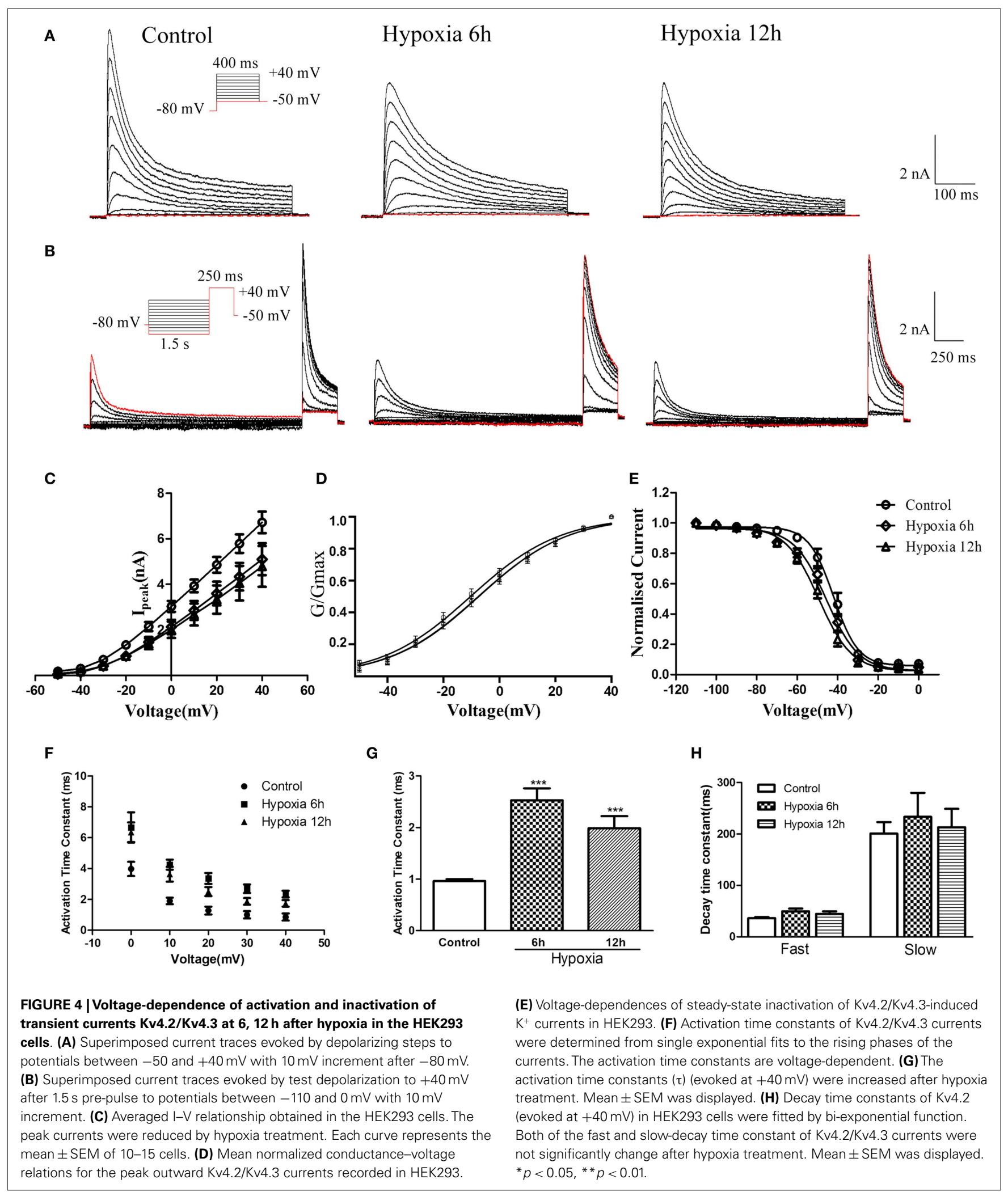

is a potent regulator of channel activity for multiple ion channel types (Bahring et al., 2001; Su et al., 2007). Furthermore, $\operatorname{Kv} \beta 1.2$ could regulate the redox and oxygen sensitivity of the
Kv4.2 currents (Perez-Garcia et al., 1999). Thus, redox modulation resulting from hypoxia could be a mechanism of altered channel function. 
However, the decrease of $I_{A}$ after hypoxia treatment in the current study is different from previous studies on $\mathrm{I}_{\mathrm{A}}$ during hypoxia. Deng et al. (2011) reported that $\mathrm{I}_{\mathrm{A}}$ was up-regulated in ischemia-resistant large aspiny neurons and other studies have shown increased potassium currents during hypoxia (Leblond and Krnjevic, 1989). Variation in the results of previous reports and our observations could be attributed to multiple experimental variables that include the preparation (brain slice vs. cultured cells), the time and severity of hypoxia, and the comparison of native versus recombinant channels. Nonetheless, our data provide evidence that Kv4 channel function can be directly modulated by hypoxia in a manner to decrease $\mathrm{I}_{\mathrm{A}}$ and promote membrane excitability.

A-type potassium currents play a critical role in action potential repolarization and inhibition of burst firing in many types of neurons and cardiac muscle (Castro et al., 2001; Kim et al., 2005). $I_{A}$ in neuronal dendrites also contributes to the resting membrane potential and regulates firing frequency (Birnbaum et al., 2004). The reduction of $I_{A}$ by hypoxia could increase action potential half-widths and shorten the latency to the first action potential compared to physiological conditions (Peng et al., 2013). This shortened latency also increases the probability of action potential generation in response to synaptic excitation and can change a repetitive firing pattern to burst firing, thus increasing the excitability of the neuron. Further studies have indicated that the recovery from inactivation of $\mathrm{I}_{\mathrm{A}}$ can be altered by hypoxia (Ruschenschmidt et al., 2006). Although this could functionally inhibit $I_{A}$, our previous study indicated that the speed of recovery from $\mathrm{I}_{\mathrm{A}}$ inactivation was not altered by hypoxia (Peng et al., 2013).

The signaling mechanisms for $\mathrm{I}_{\mathrm{A}}$ inhibition by hypoxia in the current study are speculative. Activation of PKA or PKC can shift the activation curve of $\mathrm{I}_{\mathrm{A}}$ in a depolarizing direction in hippocampal area CA1 dendrites (Birnbaum et al., 2004). Furthermore, the inhibition of $\mathrm{I}_{\mathrm{A}}$ induced by glial cell line-derived neurotrophic factor (GDNF) is mediated by ERK/MAPK (Yang et al., 2001). Kv4.2 is expressed on dendrites in CA1 pyramidal neurons and likely forms the pore-forming subunits of $\mathrm{I}_{\mathrm{A}}$ channels in this area (Jerng et al., 2004). It is worth noting that Kv4.2 is a substrate for ERK in vitro and in hippocampal pyramidal neurons (Adams et al., 2000), so Kv4.2 is a target for regulation by ERK/MAPK. It is likely that kinase phosphorylation of Kv4.2 decreases the probability of channel opening or the number of channels in the dendritic membrane, and thus, this could have been a mechanism of decreased $\mathrm{I}_{\mathrm{A}}$.

In summary, the current study showed a down-regulation of Kv4.2 mRNA and protein and Kv4.3 channels mRNA after hypoxia treatment in vitro, consistent with decreased channel expression after seizure-inducing hypoxia in neonatal rat in vivo. Brief hypoxia exposure induced the inhibition of peak $\mathrm{I}_{\mathrm{A}}$. In addition, the time constant of activation of $\mathrm{I}_{\mathrm{A}}$ was increased by hypoxia. The down-regulation of A-type channels by hypoxia may play a role in the development of neonatal seizures that result from an hypoxic episode, and our data raised possible mechanisms of direct Kv4 channel regulation by hypoxia.

\section{ACKNOWLEDGMENTS}

This work was supported by the National Natural Sciences Foundation of China (No. 81100970, 81370737, and 81371422), the
National Basic Research Program of China (2010CB529803) and the Fundamental Research Funds for the Central Universities. Part of this manuscript is the result of work supported with resources and the use of facilities at the Central Texas Veterans Health Care System, Temple, TX, USA.

\section{SUPPLEMENTARY MATERIAL}

The Supplementary Material for this article can be found online at http://www.frontiersin.org/Journal/10.3389/fncel.2014.00329/ abstract

\section{REFERENCES}

Adams, J. P., Anderson, A. E., Varga, A. W., Dineley, K. T., Cook, R. G., Pfaffinger, P. J., et al. (2000). The A-type potassium channel Kv4.2 is a substrate for the mitogen-activated protein kinase ERK. J. Neurochem. 75, 2277-2287. doi:10.1046/j.1471-4159.2000.0752277.x

Archer, S. L., London, B., Hampl, V., Wu, X., Nsair, A., Puttagunta, L., et al. (2001). Impairment of hypoxic pulmonary vasoconstriction in mice lacking the voltagegated potassium channel Kv1.5. FASEB J. 15, 1801-1803.

Archer, S. L., Souil, E., Dinh-Xuan, A. T., Schremmer, B., Mercier, J. C., El Yaagoubi, A., et al. (1998). Molecular identification of the role of voltage-gated K+ channels, Kv1.5 and Kv2.1, in hypoxic pulmonary vasoconstriction and control of resting membrane potential in rat pulmonary artery myocytes. J. Clin. Invest. 101, 2319-2330. doi:10.1172/JCI333

Bahring, R., Milligan, C. J., Vardanyan, V., Engeland, B., Young, B. A., Dannenberg, J., et al. (2001). Coupling of voltage-dependent potassium channel inactivation and oxidoreductase active site of Kvbeta subunits. J. Biol. Chem. 276, 22923-22929. doi:10.1074/jbc.M100483200

Banasiak, K. J., Burenkova, O., and Haddad, G. G. (2004). Activation of voltagesensitive sodium channels during oxygen deprivation leads to apoptotic neuronal death. Neuroscience 126, 31-44. doi:10.1016/S0306-4522(03)00425-1

Bernard, C., Anderson, A., Becker, A., Poolos, N. P., Beck, H., and Johnston, D. (2004). Acquired dendritic channelopathy in temporal lobe epilepsy. Science 305, 532-535. doi:10.1126/science.1097065

Birnbaum, S. G., Varga, A. W., Yuan, L. L., Anderson, A. E., Sweatt, J. D., and Schrader, L. A. (2004). Structure and function of Kv4-family transient potassium channels. Physiol. Rev. 84, 803-833. doi:10.1152/physrev.00039.2003

Castro, P. A., Cooper, E. C., Lowenstein, D. H., and Baraban, S. C. (2001). Hippocampal heterotopia lack functional Kv4.2 potassium channels in the methylazoxymethanol model of cortical malformations and epilepsy. J. Neurosci. 21, 6626-6634.

Chao, D., and Xia, Y. (2010). Ionic storm in hypoxic/ischemic stress: can opioid receptors subside it? Prog. Neurobiol. 90, 439-470. doi:10.1016/j.pneurobio.2009. 12.007

Chi, X. X., and Xu, Z. C. (2000). Differential changes of potassium currents in CA1 pyramidal neurons after transient forebrain ischemia. J. Neurophysiol. 84, 2834-2843.

Conforti, L., Bodi, I., Nisbet, J. W., and Millhorn, D. E. (2000). O2-sensitive K+ channels: role of the Kv1.2 subunit in mediating the hypoxic response. J. Physiol. 524(Pt 3), 783-793. doi:10.1111/j.1469-7793.2000.00783.x

Conforti, L., Petrovic, M., Mohammad, D., Lee, S., Ma, Q., Barone, S., et al. (2003a). Hypoxia regulates expression and activity of Kv1.3 channels in T lymphocytes: a possible role in T cell proliferation. J. Immunol. 170, 695-702. doi:10.4049/jimmunol.170.2.695

Conforti, L., Takimoto, K., Petrovic, M., Pongs, O., and Millhorn, D. (2003b). The pore region of the Kv1.2alpha subunit is an important component of recombinant Kv1.2 channel oxygen sensitivity. Biochem. Biophys. Res. Commun. 306, 450-456. doi:10.1016/S0006-291X(03)00989-6

Cummins, T. R., Donnelly, D. F., and Haddad, G. G. (1991). Effect of metabolic inhibition on the excitability of isolated hippocampal CA1 neurons: developmental aspects. J. Neurophysiol. 66, 1471-1482.

Deng, P., Pang, Z. P., Lei, Z., Shikano, S., Xiong, Q., Harvey, B. K., et al. (2011). Up-regulation of A-type potassium currents protects neurons against cerebral ischemia. J. Cereb. Blood Flow Metab. 31, 1823-1835. doi:10.1038/jcbfm.2011.88

Gao, T. M., and Fung, M. L. (2002). Decreased large conductance $\mathrm{Ca}(2+)$ activated $\mathrm{K}(+)$ channel activity in dissociated CA1 hippocampal neurons in 
rats exposed to perinatal and postnatal hypoxia. Neurosci. Lett. 332, 163-166. doi:10.1016/S0304-3940(02)00946-1

Gebhardt, C., and Heinemann, U. (1999). Anoxic decrease in potassium outward currents of hippocampal cultured neurons in absence and presence of dithionite. Brain Res. 837, 270-276. doi:10.1016/S0006-8993(99)01616-9

Huang, H. Y., Cheng, J. K., Shih, Y. H., Chen, P. H., Wang, C. L., and Tsaur, M. L. (2005). Expression of A-type K channel alpha subunits $\mathrm{Kv} 4.2$ and $\mathrm{Kv} 4.3$ in rat spinal lamina II excitatory interneurons and colocalization with painmodulating molecules. Eur. J. Neurosci. 22, 1149-1157. doi:10.1111/j.1460-9568. 2005.04283.x

Hulme, J. T., Coppock, E. A., Felipe, A., Martens, J. R., and Tamkun, M. M. (1999). Oxygen sensitivity of cloned voltage-gated $\mathrm{K}(+)$ channels expressed in the pulmonary vasculature. Circ. Res. 85, 489-497. doi:10.1161/01.RES.85.6.489

Hyllienmark, L., and Brismar, T. (1996). Effect of metabolic inhibition on K+ channels in pyramidal cells of the hippocampal CA1 region in rat brain slices. J. Physiol. 496(Pt 1), 155-164.

Ito, T., Nuriya, M., and Yasui, M. (2010). Regulation of Kv2.1 phosphorylation in an animal model of anoxia. Neurobiol. Dis. 38, 85-91. doi:10.1016/j.nbd.2010. 01.002

Jerng, H. H., Pfaffinger, P. J., and Covarrubias, M. (2004). Molecular physiology and modulation of somatodendritic A-type potassium channels. Mol. Cell. Neurosci. 27, 343-369. doi:10.1016/j.mcn.2004.06.011

Jiang, B., Sun, X., Cao, K., and Wang, R. (2002). Endogenous Kv channels in human embryonic kidney (HEK-293) cells. Mol. Cell. Biochem. 238, 69-79. doi:10.1023/A:1019907104763

Kim, J., Wei, D. S., and Hoffman, D. A. (2005). Kv4 potassium channel subunits control action potential repolarization and frequency-dependent broadening in rat hippocampal CA1 pyramidal neurones. J. Physiol. 569, 41-57. doi:10.1113/jphysiol.2005.095042

Lawson, K. (2000). Potassium channel openers as potential therapeutic weapons in ion channel disease. Kidney Int. 57, 838-845. doi:10.1046/j.1523-1755.2000. 00923.x

Leblond, J., and Krnjevic, K. (1989). Hypoxic changes in hippocampal neurons. J. Neurophysiol. 62, 1-14.

Lopez-Barneo, J., Pardal, R., and Ortega-Saenz, P. (2001). Cellular mechanism of oxygen sensing. Annu. Rev. Physiol. 63, 259-287. doi:10.1146/annurev.physiol. 63.1.259

Melamed-Frank, M., Terzic, A., Carrasco, A. J., Nevo, E., Avivi, A., and Levy, A. P. (2001). Reciprocal regulation of expression of pore-forming KATP channel genes by hypoxia. Mol. Cell. Biochem. 225, 145-150. doi:10.1023/A:1012286624993

Misonou, H., Mohapatra, D. P., Menegola, M., and Trimmer, J. S. (2005). Calciumand metabolic state-dependent modulation of the voltage-dependent Kv2.1 channel regulates neuronal excitability in response to ischemia. J. Neurosci. 25, 11184-11193. doi:10.1523/JNEUROSCI.3370-05.2005

Osipenko, O. N., Tate, R. J., and Gurney, A. M. (2000). Potential role for kv3.1b channels as oxygen sensors. Circ. Res. 86, 534-540. doi:10.1161/01.RES.86.5.534

Patel, A. J., and Honore, E. (2001). Molecular physiology of oxygen-sensitive potassium channels. Eur. Respir. J. 18, 221-227. doi:10.1183/09031936.01.00204001

Patel, A. J., Lazdunski, M., and Honore, E. (1997). Kv2.1/Kv9.3, a novel ATPdependent delayed-rectifier $\mathrm{K}+$ channel in oxygen-sensitive pulmonary artery myocytes. EMBO J. 16, 6615-6625. doi:10.1093/emboj/16.22.6615

Peng, B. W., Justice, J. A., He, X. H., and Sanchez, R. M. (2013). Decreased Acurrents in hippocampal dentate granule cells after seizure-inducing hypoxia in the immature rat. Epilepsia 54, 1223-1231. doi:10.1111/epi.12150
Perez-Garcia, M. T., Lopez-Lopez, J. R., and Gonzalez, C. (1999). Kvbeta1.2 subunit coexpression in HEK293 cells confers O2 sensitivity to kv4.2 but not to Shaker channels. J. Gen. Physiol. 113, 897-907. doi:10.1085/jgp.113.6.897

Perez-Garcia, M. T., Lopez-Lopez, J. R., Riesco, A. M., Hoppe, U. C., Marban, E., Gonzalez, C., et al. (2000). Viral gene transfer of dominant-negative Kv4 construct suppresses an $\mathrm{O} 2$-sensitive $\mathrm{K}+$ current in chemoreceptor cells. J. Neurosci. 20, 5689-5695.

Ruschenschmidt, C., Chen, J., Becker, A., Riazanski, V., and Beck, H. (2006). Functional properties and oxidative modulation of A-type $\mathrm{K}$ currents in hippocampal granule cells of control and chronically epileptic rats. Eur. J. Neurosci. 23, 675-685. doi:10.1111/j.1460-9568.2006.04608.x

Serodio, P., and Rudy, B. (1998). Differential expression of Kv4 K+ channel subunits mediating subthreshold transient $\mathrm{K}+$ (A-type) currents in rat brain. J. Neurophysiol. 79, 1081-1091.

Su, Z., Limberis, J., Martin, R. L., Xu, R., Kolbe, K., Heinemann, S. H., et al. (2007). Functional consequences of methionine oxidation of hERG potassium channels. Biochem. Pharmacol. 74, 702-711. doi:10.1016/j.bcp.2007.06.002

Thomas, P., and Smart, T. G. (2005). HEK293 cell line: a vehicle for the expression of recombinant proteins. J. Pharmacol. Toxicol. Methods 51, 187-200. doi:10.1016/j.vascn.2004.08.014

Wang, D., Youngson, C., Wong, V., Yeger, H., Dinauer, M. C., Vega-Saenz Miera, E., et al. (1996). NADPH-oxidase and a hydrogen peroxide-sensitive $\mathrm{K}+$ channel may function as an oxygen sensor complex in airway chemoreceptors and small cell lung carcinoma cell lines. Proc. Natl. Acad. Sci. U.S.A. 93, 13182-13187. doi:10.1073/pnas.93.23.13182

Wang, J., Juhaszova, M., Rubin, L. J., and Yuan, X. J. (1997). Hypoxia inhibits gene expression of voltage-gated $\mathrm{K}+$ channel alpha subunits in pulmonary artery smooth muscle cells. J. Clin. Invest. 100, 2347-2353. doi:10.1172/JCI119774

Wulff, H., Castle, N. A., and Pardo, L. A. (2009). Voltage-gated potassium channels as therapeutic targets. Nat. Rev. Drug Discov. 8, 982-1001. doi:10.1038/ $\operatorname{nrd} 2983$

Yang, F., Feng, L., Zheng, F., Johnson, S. W., Du, J., Shen, L., et al. (2001). GDNF acutely modulates excitability and A-type $\mathrm{K}(+)$ channels in midbrain dopaminergic neurons. Nat. Neurosci. 4, 1071-1078. doi:10.1038/nn734

Yuan, J. X. (2001). Oxygen-sensitive K(+) channel(s): where and what? Am. J. Physiol. Lung Cell Mol. Physiol. 281, L1345-L1349.

Conflict of Interest Statement: The authors declare that the research was conducted in the absence of any commercial or financial relationships that could be construed as a potential conflict of interest.

Received: 04 August 2014; accepted: 29 September 2014; published online: 14 October 2014.

Citation: Liu Y-Q, Huang W-X, Sanchez RM, Min J-W, Hu J-J, He X-H and Peng B-W (2014) Regulation of Kv4.2 A-type potassium channels in HEK-293 cells by hypoxia. Front. Cell. Neurosci. 8:329. doi: 10.3389/fncel.2014.00329

This article was submitted to the journal Frontiers in Cellular Neuroscience.

Copyright (C) 2014 Liu, Huang, Sanchez, Min, Hu, He and Peng. This is an open-access article distributed under the terms of the Creative Commons Attribution License (CC $B Y)$. The use, distribution or reproduction in other forums is permitted, provided the original author(s) or licensor are credited and that the original publication in this journal is cited, in accordance with accepted academic practice. No use, distribution or reproduction is permitted which does not comply with these terms. 